A Patient Reported Outcome Measure of Spiritual care as delivered by Chaplains

Corresponding author:

\title{
AUSTYN SNOWDEN
}

School of Health and Social Care, Edinburgh Napier University, Edinburgh, Scotland, UK

\section{IAIN TELFER}

Department of Spiritual \& Pastoral Care, The Royal Infirmary of Edinburgh, Edinburgh, Scotland, UK

Address correspondence to Austyn Snowden, Chair in Mental Health, School of Health and Social Care, Edinburgh Napier University, Sighthill Ct., Edinburgh EH11 4BN, UK. E-mail:

A.snowden@napier.ac.uk 
A Patient Reported Outcome Measure of Spiritual Care as delivered by Chaplains

\begin{abstract}
Chaplains are employed by health organizations around the world to support patients in recognizing and addressing their spiritual needs. There is currently no generalizable measure of the impact of these interventions and so the clinical and strategic worth of chaplaincy is difficult to articulate. This paper introduces the Scottish PROM, an original five-item patient reported outcome measure constructed specifically to address this gap. It describes the validation process from its conceptual grounding in the spiritual care literature through face and content validity cycles. It shows that the Scottish PROM is internally consistent and unidimensional. Responses to the Scottish PROM show strong convergent validity with responses to the Warwick and Edinburgh Mental Well-Being Scale, a generic well-being scale often used as a proxy for spiritual well-being. In summary, the Scottish PROM is fit for purpose. It measures the outcomes of spiritual care as delivered by chaplains in this study. This novel project introduces an essential and original breakthrough; the possibility of generalizable international chaplaincy research.
\end{abstract}




\section{INTRODUCTION}

Health services across the world employ chaplains ${ }^{1}$ to deliver spiritual care (Cramer \& Tenzek, 2012; Marin et al., 2015; Vlasblom, et al 2014). This is because people have needs over and above their physical or psychological requirements (Kelly, 2012). However, unlike physical and psychological needs it is difficult to know when someone’s spiritual needs have been met, or what the outcome of meeting those needs may be. This is important for managers faced with difficult decisions as to how best to deploy limited health resources (Palfreyman, 2011). In order to make strategic decisions planners need to understand how effective care is so they can best meet the needs of the population. They need to understand the outcome of treatment rather than just its cost (Porter \& Teisberg, 2007) so they can focus resources on the most effective care. Latkovic (2013) claims that shifting to an outcomes based payment system could save US $\$ 1$ trillion. The need to be able to provide evidence of impact in terms of outcomes has never been greater.

The evidence for the impact of chaplain interventions is weak. It is known that chaplains can improve patient satisfaction with hospital stays (Marin et al., 2015), and there are many case studies of successful individual encounters (Fitchett, 2011). This is important work, but case studies and satisfaction measures are weak indicators of impact. Research hierarchies generally favor transferable, generalizable, objective data (Kirkpatrick \& Kirkpatrick, 1994), certainly in decisions on funding treatment in national health services (SIGN, 2010). Chaplaincy leaders worldwide therefore recognize that outcomes of chaplaincy interventions need to be measured in order to provide a stronger evidence base (Healthcare Chaplaincy Network, 2016).

Healthcare Chaplaincy Network (2016) recently recommended that chaplains use a range of tools to measure different elements of spiritual care. The reason they had to recommend a range of tools is because there is no tool designed to specifically measure patient outcomes of chaplain interventions. The purpose of this paper is to introduce the first measure designed to this end: The Scottish Patient Reported Outcome Measure (PROM). 
The Scottish PROM is theoretically grounded in a Scottish interpretation of spirituality and chaplaincy. It is important to stress this cultural element early, because it is clear that chaplains deliver a range of interventions that vary according to country and context. For example Handzo et al., (2008), in their investigation of chaplain activity in New York, found chaplains delivering religious/spiritual interventions but also more general interventions such as advocacy and counselling. Flannelly, Oettinger, Galek, Braun-Storck, \& Kreger, (2009) make a further distinction by incorporating emotional interventions, with different types of chaplain activity targeting different needs. It is beyond the scope of this paper to attempt a synthesis of this extensive literature. The point is that chaplains worldwide deliver a wide and variable range of interventions according to need. The range of interventions is likely to change according to the local culture. In Scotland, Mowat and Swinton (2007, p. 8) found the core task of Scottish chaplaincy to involve "an active process of finding people who need spiritual care, identifying the nature of the need and responding to the need through theological reflection and the sharing of spiritual practices.”

Mowat and Swinton (2007) started from the assumption that whatever chaplains did would be spiritual in nature, whether it be praying, ritual, advocacy or counselling. They then went on to deconstruct the activities of chaplains in order to clarify specialist spiritual care interventions and their impact. These activities are discussed in more detail below as they underpin the development of the PROM. The impact of using this theoretical ground on the generalizability of the Scottish PROM to other cultures will be discussed later.

\section{METHODS}

\section{Patient Reported Outcome Measure and COSMIN Checklist}

A patient reported outcome measure (PROM) is a measure of health, as defined by the patient, in relation to treatment they have received (Wolpert, 2014). PROMs are widely used across health services internationally, and are used to inform care planners and deliverers whether the care they 
provide is effective or not. The best PROMs are short, easy to understand and important to the group under study (Meadows, 2010). They are psychometrically valid and reliable, and ideally measure a unidimensional construct (Fries, Rose, \& Krishnan, 2011). This paper systematically details the development of the Scottish PROM to show that it meets these criteria. It follows the COSMIN criteria for reporting on the measurement properties of an original PROM (Mokkink, Terwee, Knol, et al., 2010; Mokkink, Terwee, Patrick, et al., 2010). These criteria are: theoretical underpinning, item development, face and content validity, reliability, dimensionality, construct validity. These are discussed in turn.

\section{THEORETICAL UNDERPINNING}

The Scottish PROM is designed to be a single scale measure of patient outcomes of chaplaincy interventions. Higher scores on the Scottish PROM should indicate better outcomes. The first steps in the construction of the measure were to clarify patient outcomes of chaplaincy interventions. The literature was then searched for existing measures designed to quantify these outcomes.

As discussed in the introduction, because the PROM was developed in and for Scotland, it is grounded in Mowat and Swinton’s (2007) seminal research, “What Chaplains Do.” Despite finding a broad range of activity Mowat and Swinton (2007) noted consistent recurrent elements such as chaplains listening to people and helping them to talk about what was on their mind. Key themes included honesty, control, hope, facilitating a better outlook, giving comfort, understanding, listening, and helping people achieve peace. See Snowden et al, (2012, p. 7, Fig 2.1) for complete list.

As a function of this chaplain activity people reported feeling less anxious and more at peace. They felt a greater capacity to be honest. They reported a greater sense of control and felt better understood. So, while it was not their primary goal, Mowat and Swinton (2007) nevertheless 
generated a set of consistent consequences of chaplain activity that could be considered outcomes (Snowden, Telfer, Kelly, Bunniss, \& Mowat, 2013). Outcomes of chaplain interventions included: control, peace, lessening anxiety, honesty, comfort, relief from distress, being understood, feeling hopeful, being able to cope, and having a positive outlook on life.

In order to search for existing psychometric tools designed to measure these themes the literature search string used by Mowat and Swinton (2007) was updated and expanded as follows. The following terms were combined in multiple searches in Medline, Cinahl, Psychinfo, Mendeley, Google Scholar, Cochrane library: Chaplain* AND (patient reported outcome measure OR measure AND comfort OR hope OR intervention OR spirit* OR cope OR anxi* OR understand* OR listen* OR acknowledge* OR 'chance to talk' OR gratitude OR serenity OR peace OR control).

Searching was an iterative process. For example, obviously the search term "measure” is incorporated within "patient reported outcome measure" and so "patient reported outcome measure" is therefore a redundant term if the purpose was to ascertain every paper with the word "measure" in it. However, on some searches "measure” generated too many irrelevant results and so the longer term functioned better. In other cases, the opposite was true, when the longer measure did not generate enough relevant papers, but substituting "measure” for it revealed relevant papers on psychometric properties of spiritual care measures that would otherwise have been missed.

The end result of this theoretical phase was a set of potential outcomes of chaplaincy interventions grounded in the literature on chaplaincy and spiritual care and the identification of a number of tools designed to measure these attributes. A summary of key studies, key measures and their salience to the development of the PROM is in the Appendix.

\section{ITEM DEVELOPMENT}

The next phase was to turn these initial findings into items that could populate the Scottish PROM. This was achieved by inviting patient groups and chaplains to construct statements clearly 
connected to each theme (Snowden \& Telfer, 2011). The focus at this stage was on brevity and clarity. For example, for the theme of "being listened to" the statement was: "I was listened to". Table 1 shows examples of each theme and the original statement associated with it. Comparable items from other questionnaires are also shown. While there are sometimes similarities between the items all the Scottish PROM items are original.

\section{Table 1 here please}

The PROM items were discussed and refined over a further series of workshops with chaplains, service users and international leaders in spiritual care throughout 2011 and 2012. The first workshop in June 2011 was attended by 40 Scottish chaplains (Snowden \& Telfer, 2011). The main concern at this stage was whether the outcomes were "chaplain specific” enough. For example, hope and peace could be facilitated by any competent health professional. The spiritual element appeared missing to many, although most felt that spirituality was implicit in the items. One of the key decisions made in these workshops was that avoiding explicitly religious or mystical terms was important if the PROM was to be relevant to everybody. Scottish chaplains report that many patients who see them and appear to benefit from their interventions, do not describe themselves as either spiritual or religious.

This is consistent with recent census data that shows 37\% Scottish population declare themselves having no religion/faith, a 9\% increase on the previous census. ${ }^{2}$ Scotland is a secular nation and increasingly so. This means that adding overtly spiritual items to the PROM could exclude 37\% Scottish population, many of whom appear to benefit from seeing a chaplain (Tennant et al., 2007). Nevertheless, this absence of religious and spiritual items continued to worry some chaplains, so a section was added to the pilot version of the PROM to ascertain spiritual traits of the participants responding. The purpose of adding the items was to see if there was any relationship between them and responses to the items in the PROM. The spiritual items were taken from Galek et al (2005): “A need to experience love and belonging”; :A need to live an ethical and moral life”; “A need to 
experience beauty, music or nature”; “A need to feel hopeful”; “A need for peace and contentment”; "A need to feel thankful or grateful”; and "A need to find meaning and purpose in life."

The pilot study showed no relationship between responses to these items and responses to the PROM, further supporting the claim that all people got equivalent benefit from seeing chaplains regardless of faith perspective (Snowden et al, 2013a). This finding that chaplains are of benefit to all people regardless of faith has helped other health professionals better understand the modern role of the healthcare chaplain. For example, in an ongoing study it has helped General Practitioners assuage fears some people have had about the religious element of chaplaincy on being referred to see them. However, this is not to say that someone's beliefs are not relevant. Chaplains need to understand a patient's faith in order to deliver individualized care. More work is needed, and in order to better understand any relationship between religiosity and chaplaincy impact subsequent versions of the PROM have contained a shortened demographic/trait question asking people if they were spiritual/religious, both or neither.

One of the other key purposes of the workshops was to reduce the number of items where possible. The preference is for short scales because people are more likely to complete them, and so the focus of the following workshop was to reduce the number of items down to the core and essential items (Pilkonis et al, 2011). Where one item could be considered to be subsumed within another then the subsumed item was removed. For example, "hope" is a function of "having a better outlook on life.” "Distress” can be subsumed into the more general term "anxiety.” The items focusing on hope and distress were therefore removed. Consensus was reached on concentrating on five key overarching outcomes: control, peace, anxiety, honesty and having a positive outlook on life (Snowden \& Telfer, 2012). These outcomes were then turned into Likert type items. The stem (the wording at the beginning of the PROM) included a two-week timeframe in order to align it conceptually with comparable measures such as WEMWBS. The purpose of the two-week timeframe 
is to allow for reflection over a longer period of time and not just report a snapshot of experience at any given moment.

\section{FACE AND CONTENT VALIDITY}

The five items were then tested for face and content validity in expert panels at an international conference attended by world leaders in chaplain research (Snowden \& Telfer, 2012). At this stage it was suggested that a free text box be added so that patients could elaborate on their outcomes should they so wish. The final test of face and content validity involved a pilot study of the PROM in a cohort of patients who had received spiritual care from chaplains in NHS Lothian, Scotland (Snowden et al, 2013a). The pilot study asked participants to complete and return the PROM after their episode of care had finished and also provide any comments on its relevance and understandability.

This pilot showed that the PROM was understandable and relevant to participants. The items were unambiguous. Minor amendments to the wording of the items were made as a consequence of feedback (Snowden \& Telfer, 2015). For example, “I had a better outlook” was changed to "I had a positive outlook” because the latter does not infer any previous state (a worse outlook). The version tested here consisted of a stem: "In the last two weeks I have felt," and the following items: "I could be honest with myself about how I was really feeling 'Anxious””; “I had a positive outlook on my situation”; "In control of my life”; and “A sense of peace.” Each item was followed by a Likert response from "none of the time" through "rarely," "some of the time," and "often” to "all of the time.” This version was tested for reliability, dimensionality and convergent validity with a comparable relevant measure in a national sample of people seeing chaplains in Scotland in 20152016.

\footnotetext{
RELIABILITY, DIMENSIONALITY, CONSTRUCT VALIDITY.
} 
The objectives of this phase of validation were to: (1) Establish the reliability of the Scottish PROM; (2) Examine the dimensionality of the Scottish PROM; And (3) Establish convergent validity of the Scottish PROM against a validated well-being measure. The study hypotheses were: (1) The Scottish PROM will show strong reliability; (2) The Scottish PROM will demonstrate unidimensionality; and (3) The Scottish PROM will demonstrate convergent validity with WEMWBS.

The hypotheses were tested using a non-experimental design. Project participants were all patients discharged from a community chaplaincy listening service between September 2014 and March 2016. Community chaplaincy listening (CCL) is a service delivered by chaplains in general practice health care centres across Scotland to people in distress. The chaplain's intervention is to listen, or more specifically 'careful, agenda free listening' (Mowat et al., 2013, p. 36). One chaplain described the listening as "Helping people unravel the events going on in their lives so that they can make meaning, find purpose and strength and a hopeful way forward” (Mowat et al, 2013, p. 39).

Patients were referred to CCL by their general practitioners. Patients met with the chaplain and then had as many sessions as they needed to tell their story, consider the issues they are facing and move towards some sense of resolution or peace. Sessions routinely lasted 50 minutes and patients were free to discharge themselves from the listening service at any time, without explanation.

\section{Ethics}

Permission for the study was obtained from NHS West of Scotland research ethics committee 4 on $23^{\text {rd }}$ June 2014, ref 14/WS/0083. Local R\&D permissions were obtained from 11 NHS Scotland Health boards. All people who had received CCL were included. Children under 16, people unable to consent and people who had been very recently bereaved (within six months) were excluded. The bereavement 
criterion was a stipulation of the ethics committee. Data were collected over 18-month period 2014-2016. The CCL programme began in 2011.

Procedure

People who had attended CCL who had been subsequently discharged from the service were sent a questionnaire pack. The pack contained the Scottish PROM and the Warwick and Edinburgh Mental Wellbeing Scale (WEMWBS). The WEMWBS was chosen as the comparator because it is a popular measure of general mental wellbeing (Stewart-Brown, 2013; Stewart-Brown et al., 2009) and so should demonstrate some convergence with the Scottish PROM. Further, the WEMWBS has been used in a UK study where chaplains wanted to measure their impact (Kevern \& Hill, 2015), and so there is the possibility of benchmarking scores on the PROM. Finally, WEMWBS has been validated in many different populations and countries and can therefore be considered to be consistently measuring wellbeing in general (Bartram, Yadegarfar, Sinclair, \& Baldwin, 2011; Stewart-Brown, 2014). The questionnaires also asked basic demographic questions about age, gender and whether the person was religious, spiritual, both or neither.

Scotland has fourteen health boards responsible for health services within their geographical locality. Eleven NHS Scotland boards participated in the study. Each board area had a PROM “champion,” a chaplain who coordinated research activity associated with this project in his or her own area. Following discharge from CCL the chaplain listener forwarded details of discharge to the PROM champion. The champion then forwarded a numbered (anonymized) study questionnaire to the patient. The patient then completed the questionnaire (or not) and returned it to the study administrator in the self-addressed envelope. The administrator then sent the completed anonymized database to the principal investigator. This process was designed to ensure anonymity. 
Analytic plan

Each of the five items from the Scottish PROM was coded as below with the exception of the negatively worded item about anxiety, which was reverse coded: None of the Time $=0$, Rarely $=1$, Some of the time $=2$, Most of the Time $=3$, All of the time $=4$. Missing data were treated as follows: where one of the five items was omitted an average of the other scores was used to replace that item. Where more than one item was omitted the whole set of responses were omitted from analysis. This scoring key gave a maximum possible score of 20 . The hypotheses were tested in the following way.

1. The Scottish PROM will show strong reliability

Reliability is the ability of a tool to measure a concept in a consistent way (Spiliotopoulou, 2009). Polit and Beck (2008) use the example of a scale designed to measure empathy in nursing. Such a scale should only consist of relevant items such as compassion, and not for example contain an item about diagnostic competence. Internal consistency (reliability) is a measure of how well the items measure the same trait.

Reliability is usually analyzed using Cronbach’s alpha, a measure of interrelatedness between item responses (Kottner \& Streiner, 2010). Results from the pilot study had demonstrated that the five PROM items showed strong internal consistency in a sample of 37 patients $(\alpha=0.84)$ (Snowden et al, 2013). Cronbach’s alpha was repeated in this study using SPSS version 22. Data were imported into SPSS version 22 and a reliability analysis run.

2. The Scottish PROM will represent a unidimensional construct

One of the limitations of Cronbach's alpha is that it does not test for dimensionality. Ideally the Scottish PROM should be unidimensional in that it only measures one underlying construct (Gustafsson \& Aberg-Bengtsson, 2010), in this case the outcome of spiritual care. However, Cronbach’s alpha could demonstrate strong internal consistency even if the scale under study was multidimensional, as long as 
people responded in a consistent manner. Therefore an additional test is required to examine dimensionality (Falissard, 1999).

The most rigorous method of testing for dimensionality involves Rasch analysis (Bond \& Fox, 2007; Fries et al., 2011). However, Rasch analysis requires at least 5 responses in each Likert category for meaningful analysis (Linacre, 2006) and in a study with a modest sample size this may not happen. The best alternative is to undertake a principal component analysis (PCA), where unidimensionality would be indicated by a one factor solution (Williams, Brown, \& Onsman, 2012). Bartlett’s test for sphericity was run to check correlations between the variables, and linearity and outliers were checked using scatterplot (Lund and Lund, 2015). These assumptions were met and so PCA was run in SPSS version 22.

3. The Scottish PROM will demonstrate convergent validity with WEMWBS

In order to establish that the Scottish PROM was measuring a relevant concept it was compared with an existing validated measure. For example, the two tests above could show that the PROM was reliable and unidimensional but would not tell us if the tool was measuring anything relevant. In order to do this, responses to the Scottish PROM need to be compared with responses to a relevant measure. The chosen relevant measure was the Warwick and Edinburgh Mental Wellbeing Scale, because of its use in other studies measuring well-being in people having had spiritual care interventions (Morgan \& Tan, 2015; Stewart-Brown, 2014) and it’s excellent validity in a range of populations (Maheswaran et al 2012; Tennant et al., 2007). A moderate to high positive correlation between the Scottish PROM and WEMWBS would be considered good evidence of convergent validity (Mokkink, Terwee, Patrick, et al., 2010) because the Scottish PROM should be measuring an aspect of wellbeing (as measured by WEMWBS) but not be identical. That is, the correlation should not be extremely high, because if this were the case the Scottish PROM would be measuring the same construct as the WEMWBS and thus be redundant.

A principal component analysis (PCA) was run on the five-item Scottish PROM. The suitability of PCA was assessed prior to analysis. Monotonicity was checked using scatterplot and then following 
normality tests correlations were run to test the relationship between the Scottish PROM scores and the WEMWBS scores.

Sample Size Calculation

Convergent validity entails examination of the correlation between PROM total score and WEMWBS total score. An exact test on GPower version 2 examining a correlation: bivariate model was run with the following assumptions: one tailed, correlation 0.5, alpha error .05, and 95\% power. Total sample required was 42 .

\section{RESULTS and DISCUSSION}

The total number of PROMs sent out was 252, and 103 PROMs were returned completed, for a response rate of $41 \%$. Mean (SD) age was 54.1 (15.2) years with a range of 19 to 92 years. Of those that declared their gender, there were more females $(n=61)$ than males $(n=25)$. Of the 84 respondents who declared their religion orientation, 28 described themselves as religious, 15 spiritual, four both and 37 neither. Mean(SD) total PROM score was 13 (3.3), with range 3 to 19.

Hypothesis 1: The Scottish PROM will show strong reliability

Item and scale statistics are in Table 2. Cronbach’s alpha for the full scale was .81 indicating very good reliability. Reliability estimates using Cronbach's alpha are known to fall as a function of the number of items in the scale (Spiliotopoulou, 2009), particularly below seven items (Swailes \& McIntyre-Bhatty, 2002). Given there are only five items in this scale the result is very encouraging.

\section{insert Table 2 here}

Hypothesis 2: The Scottish PROM will represent a unidimensional construct

Inspection of the correlation matrix showed that all variables had at least one correlation coefficient greater than 0.3. The overall Kaiser-Meyer-Olkin (KMO) measure was 0.78 with individual KMO measures all greater than 0.7, classifications of 'middling' to 'meritorious' 
according to Kaiser (1974). Bartlett's test of sphericity was statistically significant $(p<.0001)$, indicating that the data was likely factorizable.

PCA revealed only one component that had eigenvalue greater than one and which explained 57\% total variance. Visual inspection of the scree plot indicated that just this one component should be retained, and no rotation was therefore necessary (Lund and Lund, 2015). The interpretation of the data was consistent with the Scottish PROM measuring a unidimensional construct: in this case outcomes of chaplain intervention. Table 3 shows the component matrix for the solution, demonstrating high loadings of all items onto the single factor.

\section{insert Table 3 here}

Hypothesis 3: The Scottish PROM will demonstrate convergent validity with WEMWBS

A Pearson's product-moment correlation was run to assess the relationship between total Scottish PROM scores and total WEMWBS scores. Preliminary analyses showed the relationship to be linear with both variables normally distributed, as assessed by Shapiro-Wilk test $(p>.05)$. There was a high positive correlation between the scores, $r(101)=.803, p<.0005$, with Scottish PROM scores explaining $64 \%$ of the variation in WEMWEBS scores.

\section{GENERAL DISCUSSION}

The study is the first to report on the development and testing of an original patient reported outcome measure for spiritual care as delivered by chaplains. The introduction explained the Scottish PROM originated in the literature on "what chaplains do" (Mowat and Swinton, 2007) and the outcomes associated with these activities. It showed the iterative process of improving face and content validity in partnership with service users, chaplains and chaplain researchers, before reporting brief results of pilot testing in 2012 (Snowden, et al., 2012, 2013a). This paper then focused on assessing the Scottish PROM’s psychometric properties. These results showed the Scottish PROM to be a valid, reliable and unidimensional scale in this population. More work needs 
to be done to test the measure in different populations and contexts. Psychometric examination of test-retest and inter-rater reliability would further strengthen the credibility of the Scottish PROM. Nevertheless, this paper represents a significant, necessary and original step towards an international generalizable measure of the outcome of chaplain interventions.

The sample size was appropriate for the study and exceeded the power analysis estimate to test the study hypotheses. The use of an external measure to establish convergent validity is a further strength. Nevertheless, there are numerous potential biases impacting upon the results, broadly characterized as information bias (eg recall bias) and selection bias (Sica, 2006). They are always problematic in self-report studies such as this. For example, it can never be known how the people who chose not to participate would have responded. Those who respond to survey requests tend to be motivated to represent themselves in a positive light where possible (Furnham, 1986). As a consequence, it remains unknown how well the PROM would function as a measure of outcome in the people who did not respond. All that can be claimed in this cohort was strong internal consistency of responses and a strong correlation between responses to the PROM and responses to the WEMWBS.

The response variation (range 3-19) suggests that the Scottish PROM should be able to meaningfully detect a wide range of outcomes of spiritual care. This is important because ceiling effects are often seen in measures attempting to understand the impact of clinical encounters. For example the Care and Relational Empathy (CARE) measure (Kersten, White, \& Tennant, 2012; Mercer, Maxwell, Heaney, \& Watt, 2004) is a measure of patient satisfaction within a clinical consultation. It suffers from a marked ceiling effect, possibly related to the social desirability bias discussed above; the patient wants to be seen to be highly appreciative of the doctor (Pratt, Hibberd, Cameron, \& Maxwell, 2015). The consequence is that most responses to CARE are bunched around a high mean, just over 45 out of a possible total score of $50 .^{3}$ In other words, most people score above $90 \%$. As a consequence, it is not a particularly good method of differentiating one experience 
from another. More data is required to calibrate the PROM and establish the meaning and clinical significance of a particular score. However, the finding that the mean was relatively low (13 out of 20) and range of responses so wide is very encouraging. ${ }^{4}$

In relation to generalizability, the Scottish PROM was validated in a primary care chaplaincy listening service in Scotland. It is unknown whether its performance would be equivalent in say, acute care, or a different country (but see footnote 4). It was designed to function within a particular culture, and while this project succeeded, some of the cultural assumptions needed to make the measure fit for purpose in Scotland could endanger its generalizability to other countries. For example, colleagues outside Scotland have criticized the Scottish PROM for not being 'chaplain specific' enough. It is difficult to respond to this criticism as it usually involves anecdotal or personal interpretations of what a chaplain is. As discussed in the introduction it is not the aim of this paper to define chaplaincy beyond grounding chaplain activity in the theoretical work of Mowat and Swinton (2007), because this was the chaplain activity under study.

Further, it has been suggested, particularly in light of its strong correlation with WEMWBS, that the Scottish PROM measures mental wellbeing and not spiritual wellbeing. This argument hinges on mental and spiritual wellbeing being separate factors. Many psychologists take this stance, and attempt to identify items that are uniquely spiritual in order to construct or identify distinct spiritual factors within wellbeing measures. For example Visser, Garssen, \& Vingerhoets (2016) tested a model hypothesizing meaningfulness and trust as uniquely spiritual factors in a wellbeing measure, with peace and pleasure among others as general wellbeing factors. The idea is that by drawing such distinctions peoples’ spiritual well-being can be distinguished from peoples general wellbeing. As a result the unique added value of the chaplain can be identified. Unfortunately, they found trust did not fit the model and so concluded that it should be considered a general factor of wellbeing. Findings such as these are quite common, and even when found in a single study, factor structures often fail to replicate in subsequent studies (Snowden, Watson, Stenhouse, \& Hale, 2015) 
Vasser et al (2016) conclude their article by suggesting that a sense of meaning and purpose in life, acceptance, caring for others, connectedness with nature, transcendent experiences, and spiritual activities should be considered uniquely spiritual activities. Certainly spiritual activities should be considered spiritual activities, but this clearly begs the question of what those could be. We would argue that the rest are not necessarily uniquely spiritual.

The Scottish PROM took a different conceptual journey. Its purpose was to measure the outcomes of spiritual care as delivered by chaplains. This means it started from the assumption that chaplains deliver spiritual activities, whatever they may be. This is what they do (Mowat and Swinton, 2007). Outcomes of this care hopefully include mental wellbeing. The Scottish PROM therefore incorporates an element of mental wellbeing. However, if the PROM was solely measuring mental wellbeing, then the correlation between the PROM and the WEMWBS would be higher, because they would be measuring exactly the same thing. Results showed they were not. Rather, a strong correlation accounting for $64 \%$ variance, as found here, suggests the scales are conceptually similar up to a point, but divergent after that point. Our interpretation is that the Scottish PROM and WEMWBS represent different types of wellbeing. Because it is measuring what chaplains do, our interpretation is that the Scottish PROM measures the outcomes of spiritual care as delivered by chaplains. The measure includes mental wellbeing. It is difficult to see why it shouldn't.

There is considerable international appetite for robust, transferable measures of the impact of chaplaincy. Despite such interest no such measure has previously been developed and so chaplains and their planners have had to justify measuring aspects of spiritual care such as mood or anxiety and then describe why these particular measures may be relevant (Healthcare Chaplaincy Network, 2016). By contrast the Scottish PROM has been specifically designed and tested to provide evidence of the outcomes of chaplaincy interventions. It is the first such measure and as such there is considerable interest in its use. In the past year the research team have been contacted by colleagues in Australia, 
Tasmania, England, Wales and Canada for permission to use the tool within various spiritual care services and populations. The Scottish PROM is being translated into Dutch and Flemish. Results of these studies/projects will be published in the next few years, and will provide important information on the practical utility of the Scottish PROM in a range of settings.

The main implication for practising chaplains is that they now have a valid, dedicated, short measure to better understand the impact of their interventions. The importance of this is clear. For example, it could be used to monitor progress. It could be used as a method of referral to chaplains from fellow health professionals. Anecdotally, it has been used as a focal point for conversation during encounters by encouraging patients to reflect on their answers. It has also been used as a means of reflection for chaplains in supervision sessions. It is not a panacea, and not meant as a replacement for any other research, but it does offer a path towards generalizable evidence of impact for chaplains that is currently missing. This type of evidence is very important as it offers policymakers a better opportunity to understand the role and function of chaplains within health teams and to see their unique impact. For example it would be interesting to see how well fellow health professionals fared by comparison when evaluated using this measure.

In order to build on this work further research is required to examine the function of the Scottish PROM in a wider range of settings and populations. More data is needed to ascertain population norms and meaningful thresholds across a range of clinical settings. The clinical utility of the Scottish PROM in practice also needs more research. The next planned phases of research include this. They are: (1) To test the utility of the Scottish PROM as a before and after measure of chaplain intervention in CCL. This study will also test convergent validity with EQ5D and explore the cost effectiveness of chaplain interventions. (2) Cross-cultural validity testing in Belgian and Dutch populations. (3) Analyze the scaling properties of the PROM using Rasch Analysis. (4) PhD project critically examining the utility of the PROM in Europe. These projects are under development and more are under consideration. 


\section{CONCLUSION}

The Scottish PROM is a reliable, valid measure of the outcomes of chaplain interventions in Scotland. It is the first measure designed specifically for the purpose of measuring the impact of chaplain interventions. As such it gives chaplains, managers and budget holders a new and powerful tool to evaluate the impact of chaplaincy in a generalizable and transferable manner. This is a significant step for chaplaincy, which up to now has been reliant on case studies or non-specific measures to support their case. While case studies are essential for reflection and the professional development of chaplaincy, they do not synthesise easily, and so are of limited use to budget holders tasked with allocating ever decreasing healthcare resources to an ever increasing population. Recognising this problem, a new approach has emerged, with scholars attempting to identify uniquely spiritual elements of healthcare so that the singular contribution of the chaplain can be articulated with a much higher degree of generalizability. So far, however, this project has proved intractable for two reasons: (1) there is no consensus on what a spiritual factor would consist of, and (2) most candidates that emerge can also usually be described as pertaining to emotional or mental wellbeing, and as such are not uniquely spiritual.

The Scottish PROM escapes these criticisms because firstly it is grounded in a coherent theory of 'what chaplains do'. Secondly, instead of taking a separatist approach to defining spirituality it was instead constructed to understand 'what it is like' to receive spiritual care. The outcome of receiving spiritual care includes improvement in mental, emotional and general wellbeing. These distinctions are unlikely to be important for people in receipt of chaplain interventions. The Scottish PROM measures the outcomes of what chaplains do. 


\section{Footnotes}

${ }^{1}$ Most countries use the term chaplain but not all. In Australia chaplains are referred to as 'pastoral carers' for example. The term chaplain is used here throughout to refer to all employees of health services around the world whose role is to primarily look after the religious and spiritual needs of their population.

${ }^{2}$ Scottish religious group demographics

http://www.gov.scot/Topics/People/Equality/Equalities/DataGrid/Religion/RelPopMig

${ }^{3}$ http://www.measuringimpact.org/s4-care-measure

${ }^{4}$ An Australian study with a return of over 500 Scottish PROMs showed equivalent mean and standard deviation 


\section{REFERENCES}

Alison, A., Siddiqui, M., Snowden, A., \& Fleming, M. (2014). Faith and belief Scotland. Edinburgh. Retrieved from http://faithandbelief.div.ed.ac.uk/wp-content/uploads/2014/07/Faith-andBelief-Scotland-FINAL-VERSION-OF-REPORT.pdf

Bartram, D. J., Yadegarfar, G., Sinclair, J. M. A., \& Baldwin, D. S. (2011). Validation of the Warwick-Edinburgh Mental Well-being Scale (WEMWBS) as an overall indicator of population mental health and well-being in the UK veterinary profession. Veterinary Journal, 187(3), 397-398.

Bond, T. G., \& Fox, C. M. (2007). Applying the Rasch Model. Fundamental Measurement in the Human Sciences (2nd ed.). New York, NY: Routeledge.

Cramer, E. M., \& Tenzek, K. E. (2012). The Chaplain profession from the employer perspective: An analysis of hospice chaplain job advertisements. Journal of Health Care Chaplaincy, 18(34), 133-150. http://doi.org/10.1080/08854726.2012.720548

Falissard, B. (1999). The unidimensionality of a psychiatric scale: a statistical point of view. International Journal of Methods in Psychiatric Research, 8(3), 162-67. http://doi.org/0.1002/mpr.66

Fitchett, G. (2011). Making our case(s). Journal of Health Care Chaplaincy, 17(1-2), 3-18. http://doi.org/10.1080/08854726.2011.559829

Flannelly, K. J., Oettinger, M., Galek, K., Braun-Storck, A., \& Kreger, R. (2009). The correlates of chaplains' effectiveness in meeting the spiritual/religious and emotional needs of patients. The Journal of Pastoral Care \& Counseling, 63, 1-16. http://doi.org/10.1017/CBO9781107415324.004

Fries, J., Rose, M., \& Krishnan, E. (2011). The PROMIS of better outcome assessment: responsiveness, floor and ceiling effects, and Internet administration. The Journal of 
Rheumatology, 38(8), 1759-1764. Retrieved from

http://www.ncbi.nlm.nih.gov/pubmed/21807798

Furnham, A. (1986). Response bias, social desirability and dissimulation. Personality and Individual Differences, 7(3), 385-400.

Galek, K., Flannelly, K. J., Vane, A., \& Galek, R. M. (2005). Assessing a patient’s spiritual needs. Holistic Nursing Practice, 19(2), 62-69. Retrieved from http://www.shi.or.th/images/misc/200608011805260.pdf

Gustafsson, J.-E., \& Aberg-Bengtsson, L. (2010). Unidimensionality and interpretability of psychological instruments. Measuring Psychological Constructs: Advances in Model-Based Approaches, 97-121.

Handzo, G. F., Flannelly, K. J., Kudler, T., Fogg, S. L., Harding, S. R., Hasan, Y. H., ... Taylor, B. E. (2008). What do chaplains really do? II. Interventions in the New York chaplaincy study. Journal of Health Care Chaplaincy, 14(1), 39-56. http://doi.org/10.1080/08854720802053853

Healthcare Chaplaincy Network. (2016). What is Quality Spiritual care in Healthcare and How can we Measure it? Retrieved from http://www.healthcarechaplaincy.org/docs/research/quality_indicators_document_2_17_16.pdf

Kaiser, H. F. (1974). An index of factor simplicity. Psychometrika, 39, 31-36.

Kelly, E. (2012). The development of healthcare chaplaincy. The Expository Times, 123(10), 469478. Retrieved from http://ext.sagepub.com/content/123/10/469.short

Kersten, P., White, P. J., \& Tennant, A. (2012). The consultation and relational empathy measure: an investigation of its scaling structure. Disability and Rehabilitation, 34(August 2011), 503509.

Kevern, P., \& Hill, L. (2015). “Chaplains for well-being” in primary care: analysis of the results of 
a retrospective study. Primary Health Care Research \& Development (Cambridge University Press / UK), 16(1), 87-99 13p. http://doi.org/10.1017/S1463423613000492

Kirkpatrick, D. L., \& Kirkpatrick, J. D. (1994). Evaluating Training Programs,. Berrett-Koehler Publishers.San Francisco

Kottner, J., \& Streiner, D. L. (2010). Internal consistency and Cronbach’s alpha: A comment on Beeckman et al. (2010). International Journal of Nursing Studies, 47(7), 926-8. http://doi.org/10.1016/j.ijnurstu.2009.12.018

Latkovic, T. (2013). The trillion dollar prize. McKinsey \& Company, 1-34.

Linacre, J. M. (2006). (2006). WINSTEPS Rasch measurement computer program. Chicago: Winsteps.com.

Lund, M., Lund, A. (2015). Principal components analysis in SPSS Statistics. Retrieved from https://statistics.laerd.com/premium/pca/pca-in-spss-5.php

Maheswaran, H., Weich, S., Powell, J., \& Stewart-Brown, S. (2012). Evaluating the responsiveness of the Warwick Edinburgh Mental Well-Being Scale (WEMWBS): group and individual level analysis. Health and Quality of Life Outcomes, 10(1), 156. Retrieved from http://www.pubmedcentral.nih.gov/articlerender.fcgi?artid=3560098\&tool=pmcentrez\&render type $=$ abstract

Marin, D. B., Sharma, V., Sosunov, E., Egorova, N., Goldstein, R., \& Handzo, G. F. (2015). Relationship between chaplain visits and patient satisfaction. Journal of Health Care Chaplaincy, 21(1), 14-24. Retrieved from http://www.ncbi.nlm.nih.gov/pubmed/25569779

Meadows, K. A. (2010). Patient-reported outcome measures : an overview. British Journal of Community Nursing, 16(3), 146-151.

Mercer, S. W., Maxwell, M., Heaney, D., \& Watt, G. C. (2004). The consultation and relational 
empathy (CARE) measure: development and preliminary validation and reliability of an empathy-based consultation process measure. Family Practice, 21(6), 699-705. http://doi.org/10.1093/fampra/cmh621

Mokkink, L. B., Terwee, C. B., Knol, D. L., Stratford, P. W., Alonso, J., Patrick, D. L., ... de Vet, H. C. (2010). The COSMIN checklist for evaluating the methodological quality of studies on measurement properties: a clarification of its content. BMC Medical Research Methodology, 10(1), 22. Retrieved from http://www.biomedcentral.com/1471-2288/10/22

Mokkink, L. B., Terwee, C. B., Patrick, D. L., Alonso, J., Stratford, P. W., Knol, D. L., ... De Vet, H. C. W. (2010). The COSMIN checklist for assessing the methodological quality of studies on measurement properties of health status measurement instruments: An international Delphi study. Quality of Life Research, 19(4), 539-549.

Morgan, M., \& Tan, H. (2015). Review of Literature. Abbotsford, Victoria. Retrieved from www.spiritualhealthvictoria.org.au/LiteratureRetrieve.aspx?ID=202460

Mowat, H., \& Swinton, J. (2007). What do Chaplains do? The Role of the Chaplain in Meeting the Spiritual Needs of Patients. Aberdeen, UK. Mowat Research Ltd.

Mowat, H., Bunniss, S., Snowden, A., \& Wright, L. (2013). Listening as health care. The Scottish Journal of Healthcare Chaplaincy, 16, 39-46.

Palfreyman, S. (2011). Patient-reported outcome measures and how they are used. Nursing Older People, 23(1), 31-6. Retrieved from http://www.ncbi.nlm.nih.gov/pubmed/21323049

Pilkonis, P. A., Choi, S., Reise, S. P., \& Stover, A. M. (2011). Item banks for measuring emotional distress from the Patient Reported Outcomes Measurement Information System (PROMIS): Depression, Anxiety and Anger. Assessment, 18(3), 263-283. http://doi.org/10.1177/1073191111411667.Item 
Polit, D.F., Beck, T. B. (2008). Nursing Research. Philadelphia.: Lippincott Williams \& Wilkins.

Porter, M. E., \& Teisberg, E. O. (2007). How physicians can change the future of health care. JAMA : The Journal of the American Medical Association, 297(10), 1103-1111. http://doi.org/10.1001/jama.297.10.1103

Pratt, R., Hibberd, C., Cameron, I., \& Maxwell, M. (2015). The Patient Centered Assessment Method (PCAM): integrating the social dimensions of health into primary care. Journal of Comorbidity, 5(1), 110-119. http://doi.org/10.15256/joc.2015.5.35

Scottish Intercollegiate Guidelines Network. (2010). SIGN 50. A guideline developer’s handbook. Annex B: Key to evidence statements and grades of recommendations. Retrieved from Http://www.sign.ac.uk/guidelines/fulltext/50/annexb.html

Sica, G. T. (2006). Bias in research studies. Radiology, 238(3), 780-789. http://doi.org/10.1148/radiol.2383041109

Snowden, A., \& Telfer, I. (2011). The NHS Lothian PROM. In Spiritual Care and Bereavement Management. Edinburgh.

Snowden, A., \& Telfer, I. (2012). Spiritual care patient reported outcome measure - Why and what potential impact on practice? In Chaplaincy and Enhancing Person-Centred Care. Carberry.

Snowden, A., Telfer, I. J. ., Kelly, E. K., Bunniss, S., \& Mowat, H. (2013). "I was able to talk about what was on my mind”. The operationalisation of person centred care. The Scottish Journal of Healthcare Chaplaincy, 16, 14-24.

Snowden, A., Telfer, I., Kelly, E., Mowat, H., Bunniss, S., \& Howard, N. (2012). Healthcare Chaplaincy : the Lothian Chaplaincy Patient Reported Outcome Measure (PROM). Gourock. Retrieved from www.snowdenresearch.co.uk

Snowden, A., \& Telfer, I. (2012). A patient reported outcome measure for spiritual care. In Spiritual 
care and health: improving outcome and enhancing well being. Clydebank, Scotland.

Snowden, A., \& Telfer, I. (2015). CCL PROM: To validity and beyond. In Spiritual Wellbeing at the Heart of Person-Centred Care: Co-creating Community Through Research and Innovation. Glasgow. Retrieved from http://www.events.nes.scot.nhs.uk/media/69361/register-nowspritual-wellbeing-flyer-october15.pdf

Snowden, A., Telfer, I. J. ., Kelly, E. K., Bunniss, S., \& Mowat, H. (2013). The construction of the Lothian PROM. The Scottish Journal of Healthcare Chaplaincy, 16, 3-13.

Snowden, A., Watson, R., Stenhouse, R., \& Hale, C. (2015). Factor and Rasch Analysis of the Trait Emotional Intelligence Questionnaire Short Form. Journal of Advanced Nursing, 71(12), 2936-2949. http://doi.org/10.1111/jan.12746

Spiliotopoulou, G. (2009). Reliability reconsidered: Cronbach’s alpha and paediatric assessment in occupational therapy. Australian Occupational Therapy Journal, 56(3), 150-5. http://doi.org/10.1111/j.1440-1630.2009.00785.x

Stewart-Brown, S. (2013). The Warwick-Edinburgh Mental Well-Being Scale (WEMWBS): Performance in different cultural and geographical groups. Mental Well-Being: International Contributions to the Study of Positive Mental Health. Springer Science + Business Media.

Stewart-Brown, S. (2014). Measuring wellbeing: What does the Warwick-Edinburgh Mental Wellbeing Scale have to offer integrated care? European Journal of Integrative Medicine.

Stewart-Brown, S., Tennant, A., Tennant, R., Platt, S., Parkinson, J., \& Weich, S. (2009). Internal construct validity of the Warwick-Edinburgh Mental Well-being Scale (WEMWBS): a Rasch analysis using data from the Scottish Health Education Population Survey. Health and Quality of Life Outcomes, 7, 15.

Swailes, S., \& McIntyre-Bhatty, T. (2002). The “Belbin” team role inventory: reinterpreting reliability estimates. Journal of Managerial Psychology, 17(6), 529-536. 
Szende, A., \& Williams, A. (2004). Measuring Self-Reported Population Health: An International Perspective based on EQ-5D. Rq-5D. retreived from http://www.euroqol.org/fileadmin/user_upload/Documenten/PDF/Books/Measuring_SelfReported_Population_Health_-_An_International_Perspective_based_on_EQ-5D.pdf

Tennant, R., Hiller, L., Fishwick, R., Platt, S., Joseph, S., Weich, S., ... Stewart-Brown, S. (2007). The Warwick-Edinburgh Mental Well-being Scale (WEMWBS): development and UK validation. Health and Quality of Life Outcomes, 5, 63.

Visser, A., Garssen, B., \& Vingerhoets, A. J. (2016). Existential well-being. The Journal of Nervous and Mental Disease, 0(0), 1. http://doi.org/10.1097/NMD.0000000000000617

Vlasblom, J.P., Walton, N.P., van der Steen, J. T., Doolaard, J. J., \& Jochemsen, H. (2014).

Developments in healthcare chaplaincy in the Netherlands and Scotland: A content analysis of professional journals, 2(2). http://doi.org/10.1558/hscc.v2i2.20409

Williams, B., Brown, T., \& Onsman, A. (2012). Exploratory factor analysis : A five-step guide for novices. Australasian Journal of Paramadicine, 8(3), 1-13. Retrieved from http://ro.ecu.edu.au/cgi/viewcontent.cgi?article=1373\&context=jephc

Wolpert, M. (2014). Uses and abuses of patient reported outcome measures (PROMs): potential iatrogenic impact of PROMs implementation and how it can be mitigated. Administration and Policy in Mental Health, 41(2), 141-5. http://doi.org/10.1007/s10488-013-0509-1 
Table 1. Themes, Their Origins and Associated Items in the Pilot PROM

\begin{tabular}{|c|c|c|c|}
\hline Theme & $\begin{array}{l}\text { Example of } \\
\text { citation }\end{array}$ & $\begin{array}{l}\text { Item in pilot } \\
\text { PROM }\end{array}$ & Example validated scale and question \\
\hline Control & $\begin{array}{l}\text { (Farber et } \\
\text { al., 2010) }\end{array}$ & $\begin{array}{l}\text { I am in control of } \\
\text { my situation }\end{array}$ & Herth Hope Index (I have a sense of direction) \\
\hline Hope & $\begin{array}{l}\text { (Van Gestel- } \\
\text { Timmermans } \\
\text { et al., 2010) }\end{array}$ & $\begin{array}{l}\text { Everything is } \\
\text { going to be ok }\end{array}$ & $\begin{array}{l}\text { Herth Hope Index (I have a positive outlook } \\
\text { towards life) BDI (opposite : pessimism scale) }\end{array}$ \\
\hline $\begin{array}{l}\text { Being } \\
\text { listened to }\end{array}$ & $\begin{array}{l}\text { (Ai \& } \\
\text { McCormick, } \\
\text { 2009) }\end{array}$ & I was listened to & $\begin{array}{l}\text { GESS-R (In future I expect that I will be listened to } \\
\text { when I speak) Duke-UNC (I get chances to talk to } \\
\text { someone about problems...) }\end{array}$ \\
\hline $\begin{array}{l}\text { Being } \\
\text { understood }\end{array}$ & $\begin{array}{l}\text { (Gonzalez et } \\
\text { al., 2011) }\end{array}$ & $\begin{array}{l}\text { My situation } \\
\text { was } \\
\text { acknowledged } \\
\text { and understood }\end{array}$ & $\begin{array}{l}\text { Sources of meaning profile (being acknowledged for } \\
\text { personal achievements) Ways of Coping (WAYS) (I } \\
\text { accepted sympathy and understanding from someone) }\end{array}$ \\
\hline $\begin{array}{l}\text { Being } \\
\text { valued }\end{array}$ & $\begin{array}{l}\text { (Hebert et } \\
\text { al., 2001) }\end{array}$ & $\begin{array}{l}\text { My faith and/or } \\
\text { beliefs were } \\
\text { valued }\end{array}$ & $\begin{array}{l}\text { Spiritual Well Being Scale (I believe that God is } \\
\text { concerned about my problems) }\end{array}$ \\
\hline \multirow[t]{2}{*}{ Comfort } & $\begin{array}{l}\text { (Pargament et } \\
\text { al., 2011) }\end{array}$ & $\begin{array}{l}\text { I was able to } \\
\text { talk about what } \\
\text { was on }\end{array}$ & $\begin{array}{l}\text { Social Support Questionnaire (Whom can you count } \\
\text { on to console you when you were upset?) Brief COPE } \\
\text { (I've been trying to find comfort in my }\end{array}$ \\
\hline & & my mind & $\begin{array}{l}\text { religion or spiritual beliefs/I've been getting } \\
\text { emotional support from others) }\end{array}$ \\
\hline $\begin{array}{l}\text { Involved in } \\
\text { decisions }\end{array}$ & $\begin{array}{l}\text { (Palmer \& } \\
\text { Miedany, 2009) }\end{array}$ & $\begin{array}{l}\text { I was involved } \\
\text { in decisions } \\
\text { about my care }\end{array}$ & $\begin{array}{l}\text { GHQ (I felt capable of making decisions about } \\
\text { things) Warwick-Edinburgh Mental Well-being } \\
\text { Scale (I've been able to make up my own mind } \\
\text { about things) }\end{array}$ \\
\hline Honesty & $\begin{array}{l}\text { (Ai \& } \\
\text { McCormick, } \\
2009 \text { ) }\end{array}$ & $\begin{array}{l}\text { I could be } \\
\text { honest with } \\
\text { myself about } \\
\text { how I was } \\
\text { feeling }\end{array}$ & $\begin{array}{l}\text { CARE (How was the [chaplain] at being honest but } \\
\text { not negative about your problems) }\end{array}$ \\
\hline $\begin{array}{l}\text { Relief From } \\
\text { Distress }\end{array}$ & $\begin{array}{l}\text { (Bay et al., } \\
\text { 2008) }\end{array}$ & $\begin{array}{l}\text { My levels of } \\
\text { anxiety had } \\
\text { lessened }\end{array}$ & HADS (I can sit at ease and feel relaxed) \\
\hline $\begin{array}{l}\text { Relevant } \\
\text { information }\end{array}$ & $\begin{array}{l}\text { On faith: (Ai \& } \\
\text { McCormick, } \\
\text { 2009) On } \\
\text { illness: (Mercer } \\
\text { \& Murphy, } \\
\text { 2008b) }\end{array}$ & $\begin{array}{l}\text { I found I was } \\
\text { able to gain a } \\
\text { better } \\
\text { perspective on } \\
\text { my illness }\end{array}$ & $\begin{array}{l}\text { CARE (How was the [chaplain] at: fully answering } \\
\text { your questions, explaining clearly, giving you } \\
\text { adequate information; not being vague) }\end{array}$ \\
\hline Cope & $\begin{array}{l}\text { (Bay et al., } \\
\text { 2008) }\end{array}$ & $\begin{array}{l}\text { Things seemed } \\
\text { manageable } \\
\text { again }\end{array}$ & $\begin{array}{l}\text { [Opposite construct]: BDI screening question (Have } \\
\text { you often felt helpless about the future?) }\end{array}$ \\
\hline Peace & (Kannan, 2008) & $\begin{array}{l}\text { A sense of peace } \\
\text { that had } \\
\text { previously not } \\
\text { been there }\end{array}$ & $\begin{array}{l}\text { RCOPE (Sought help from God in letting go of my } \\
\text { anger [anger is described in this section as 'an } \\
\text { offense to peace']) }\end{array}$ \\
\hline
\end{tabular}




\section{Item-Total Statistics}

Item

$\begin{array}{cccc}\text { Scale Mean if } & \text { Scale Variance } & \text { Corrected Item- } & \text { Cronbach's } \\ \text { Item Deleted } & \text { if Item Deleted } & \text { Total } & \text { Alpha if Item } \\ & & \text { Correlation } & \text { Deleted }\end{array}$

I could be honest with myself about how I

$\begin{array}{llll}9.94 & 8.156 & .436 & .817\end{array}$

was really feeling

I had a positive outlook on my situation

10.13

7.013

.674

.752

In control of my life

10.35

6.609

.703

.740

A sense of peace

10.54

5.910

.787

.708

Anxious

10.88

7.766

.416

.828 
Table 3. Component Coefficients

\section{Component Matrix ${ }^{\mathrm{a}}$}

Item

Component

1

I could be honest with myself about how I was really feeling

I had a positive outlook on my situation

In control of my life

A sense of peace

Anxious

Extraction Method: Principal Component Analysis. ${ }^{\mathrm{a}}$

a. 1 component extracted. 


\section{Authors} Summary

(Ai \& McCormick, 2009)

(Pargament, Feuille, \& Burdzy, 2011)

(Farber et al., 2010)

(Gonzalez,

Hartig, Patil,

Martinsen, \&

Kirkevold, 2011) outcome.
Case studies are used to illustrate the actions of the chaplain at the bedside in end of life care. A new scale is presented for chaplains to assess diverse afterlife beliefs.

Pargament was the original developer of the 14 item brief RCOPE, a measure of religious coping with life stressors. The items within the scale were developed from interviews with people suffering life stressors.

Important distinction emerged between negative and positive religious coping. The negative religious coping subscale has been particularly useful as a predictor of health

This study sought to quantify the degree to which personal meaning accounted for various differences amongst a cohort of 132 people with HIV. They found that 'personal meaning' was associated with psychological well-being.

This small $(\mathrm{n}=46)$ study measured the efficacy of therapeutic horticulture on depression and in particular existential issues. The intervention significantly correlated with consistent improvement in depression but not existential issues. Existential issues were measured with the LRI-R.

\section{Measures}

Connection of

the soul (COS)

Brief RCOPE

LRI-R, GWB, MOS, Social Support

Survey, LOT-R, CHIP

LRI-R, BDI Recognition of importance of 'being with', caring and compassion as unique contribution of chaplain. Within the health care team, the chaplain is often uniquely situated as one who is designated to take time to "be with" the patient and who by both personal virtue and professional training can embody a caring and compassionate presence to the vulnerable patient.

This paper integrates discussion of psychometric quality with religious coping, a factor specifically associated with spiritual care. This may be particularly pertinent in light of discussions that suggest there is little unique to the chaplaincy role, given that other professions can claim to meet certain spiritual needs.

Personal meaning is a pertinent construct to the work of chaplaincy, so this study illuminated some of the issues in trying to account for such a variable. The Life Regard Index seems promising in this regard, although this particular study could not identify any causality because of its design.

This paper is relevant because existential issues were postulated to be relevant to chaplaincy interventions. The findings suggested that depression in this case may not be directly correlated with existential issues as measured in this way. This could be a function of the measure, the sample size or genuine discord, although the authors imply the former because the participants claimed the intervention was meaningful and influential on their view of life. These all need to be considered in PROM development. 


\section{(Hebert, Jenckes, \\ Ford, O'Connor,}

\& Cooper, 2001)

Kannan, 2008)

\section{(Van Gestel-}

Timmermans,

Van Den

Bogaard,

Brouwers, Herth,

\& Van

Nieuwenhuizen

2010)

(Bay, Beckman,

Trippi,

Gunderman, \&

Terry, 2008)
Study designed to ascertain the preferences

and concerns of seriously ill people when

discussing religious and spiritual beliefs with

clinicians. God, prayer, spiritual beliefs were all

mentioned as sources of support and healing.

Willingness to discuss these issues was closely related to the therapeutic relationship.

The purpose of this study was to describe the relationships among symptom experience, symptom management, and symptom outcome based on spiritual well-being. Kannan found that greater spiritual existential well-being was significantly associated with improved physical function.

Discusses the function of hope in recovery from mental ill- health. The study develops and validates a Dutch version of the Herth Hope Index to assess the degree to which hope may be construed and measured.

RCT studied the efficacy of chaplaincy against patient outcomes of anxiety, depression, hope, positive and negative religious coping, and religious coping styles. They found chaplain visits increased positive religious coping and decreased negative religious coping

Thematic

Relevant in ascertaining the pertinent categories of discussion and also relevant that clinicians didn't always meet these needs. In general people didn't expect clinicians to fulfill these needs but if they disclosed them then they hoped the beliefs would be valued.

Revised

Symptom Management Conceptual Model

HHI, MANSA, RAND-36, CISS, MHCS

Hamilton Anxiety and

Depression Scale (HADS); Herth Hope Index; 14 item brief RCOPE
Important because they found a relationship between self-reported spiritual well-being and physical function. This type of result supports chaplaincy from a clinical perspective. The self-report methodology makes it relevant to a potential spiritual PROM

Although the authors conclude the tool is a valid measure of hope they warn against using subscales within it in isolation. This may be due to

'interconnectedness' as being an historical factor of this index. Useful for showing how scales can and should be compared with each other in order to develop and clarify constructs like hope, loneliness and coping.

No significant differences were found between any of the major scales, suggesting it may be difficult to detect efficacy using this type of

methodology. Nevertheless, some non-significant trends towards positive religious coping were encouraging. The measures used in this study were highly pertinent to our project. 